Received 00th January 20xx, Accepted 00th January 20xx DOI: $10.1039 / x 0 x \times 00000 x$

\title{
Hydrides of early transition metals as catalysts and grain growth inhibitors for enhanced reversible hydrogen storage in nanostructured magnesium
}

\author{
Pavel Rizo-Acosta, ${ }^{a}$ Fermin Cuevas ${ }^{a}$ and Michel Latroche ${ }^{a}$ \\ Magnesium is a remarkable hydrogen storage material due to its ability to reversibly absorb high dihydrogen amount at \\ affordable cost. However, its practical use is hampered by the high thermodynamic stability of the hydride and slow \\ reaction kinetics. In this work, one-pot synthesis of nanostructrured magnesium hydride with addition of 5 mol \% of Early \\ Transition Metals ( $E T M=\mathrm{Sc}, \mathrm{Y}, \mathrm{Ti}, \mathrm{Zr}, \mathrm{V}$, and $\mathrm{Nb}$ ) as hydrogenation catalysts is accomplished by mechanochemistry under \\ hydrogen gas. Structural and hydrogenation properties have been systematically analyzed to gain a deep understanding of \\ the influence of ETMs on the hydrogenation properties of magnesium. The as-synthetized materials are nanocomposites \\ of $\mathrm{MgH}_{2}$ and ETM hydrides $\left(\mathrm{ScH}_{2}, \mathrm{YH}_{3}, \mathrm{TiH}_{2}, \mathrm{ZrH}_{2}, \mathrm{VH}\right.$ and $\left.\mathrm{NbH}\right)$ with crystallite size of $10 \mathrm{~nm}$. All nanocomposites, but \\ $\mathrm{MgH}_{2}-\mathrm{YH}_{3}$, have high reversible hydrogen storage ( $\geq 5 \mathrm{wt} . \%$ ) at $573 \mathrm{~K}$ thanks to catalytic effects induced by ETM hydrides \\ leading to fast sorption kinetics. We here demonstrate that, on desorption, ETM hydrides can catalyze the recombination \\ of hydrogen atoms. On absorption, formation of coherent interfaces between $E T M$ hydrides and $\mathrm{MgH}_{2}$ favors nucleation of \\ the latter. Moreover, for the peculiar case of $\mathrm{TiH}_{2}$, lattice mismatch between $\mathrm{Mg}$ and $\mathrm{TiH}_{2}$ hydride limits $\mathrm{Mg}$ grain growth, \\ which preserves fast absorption kinetics of $\mathrm{MgH}_{2}-\mathrm{TiH}_{2}$ nanocomposite on cycling. Thus, the best $\mathrm{H}$-cycling properties are \\ found for $\mathrm{MgH}_{2}-\mathrm{TiH}_{2}$ nanocomposite with a reversible capacity of $4.8 \mathrm{wt}$.\% after $20 \mathrm{H}$-cycles and reaction time arbitrarily \\ limited \\ to \\ $\min$
}

\section{Introduction}

Hydrogen is an attractive alternative to fossil fuels to power mobile and stationary applications. If obtained from renewable sources, hydrogen combined with oxygen produces zero emission of pollutants when used in fuel cells. Moreover, hydrogen is an ideal energy carrier due to its abundance, lowweight and high specific energy $(142 \mathrm{MJ} / \mathrm{kg})^{1}$. However, owing to its low volumetric density, compact hydrogen stores are needed to efficiently manage hydrogen production and use. One appealing storage solution, providing high volumetric hydrogen densities $\left(\sim 100 \mathrm{kgH}_{2} / \mathrm{m}^{3}\right.$ ) at safe operation conditions of pressure and temperature is hydrogen storage in solids. Magnesium hydride $\mathrm{MgH}_{2}$, with high gravimetric (7.7 wt. $\left.\% \mathrm{H}_{2}\right)$ and volumetric $\left(109 \mathrm{kgH}_{2} / \mathrm{m}^{3}\right)$ storage capacities, is an outstanding candidate for this purpose ${ }^{2}$. Nevertheless, magnesium faces two issues for being used in practical applications. Firstly, hydrogen stored in $\mathrm{MgH}_{2}$, with a decomposition enthalpy of $75 \mathrm{~kJ} / \mathrm{molH}_{2}$, is too stable ${ }^{3}$. Indeed, for feeding fuel cells, magnesium hydride should be heated above $560 \mathrm{~K}$ to release hydrogen above $0.1 \mathrm{MPa}^{4}$. Secondly, hydrogenation kinetics of bulk magnesium is extremely slow.

a. Université Paris Est, ICMPE (UMR7182), CNRS, UPEC, F-94320 Thiais, France. Electronic Supplementary Information (ESI) available: Rietveld analysis of assynthetized and $\mathrm{H}$-cycled nanocomposites. Table with molar volumes of ETM hydrides compared to $\mathrm{Mg}$ and $\mathrm{MgH}_{2}$. See DOI: $10.1039 / \mathrm{x} 0 x \times 00000 x$
For instance, complete hydrogenation of micrometric $\mathrm{Mg}$ particles requires a reaction time of several days at the previously given conditions ${ }^{5}$. Reasons for sluggish $\mathrm{H}$-kinetics in $\mathrm{Mg}$ are manifold. They are related to both surface and bulk $\mathrm{Mg}$ properties. Theoretical calculations show very poor dissociation and recombination of $\mathrm{H}_{2}$ at $\mathrm{Mg}$ surfaces for temperatures lower than $573 \mathrm{~K}^{6}$. This is aggravated by the fact that $\mathrm{Mg}$ easily forms an oxide passivation layer, even when stored in globe box ${ }^{7}$. As concerns bulk effects, the formation of a core/shell $\mathrm{Mg} / \mathrm{MgH}_{2}$ geometry in combination with the low diffusion coefficient of hydrogen in $\mathrm{MgH}_{2}$ is often pointed out as the main reason for slow hydrogen absorption in $\mathrm{Mg}^{8-}$ ${ }^{10}$. On desorption, there are also significant evidence of kinetic limitations for the nucleation and growth of $\mathrm{Mg}$ phase in $\mathrm{MgH}_{2}$ 11

To overcome these drawbacks of magnesium as hydrogen store, many strategies have been pursued, such as adding transition metals and their oxides to catalyze hydrogen dissociation and recombination ${ }^{12-15}$, alloying $\mathrm{Mg}$ with transition metals to weaken $\mathrm{Mg}-\mathrm{H}$ bonds ${ }^{16-21}$, and reducing $\mathrm{Mg}$ crystal size to the nanoscale for $\mathrm{MgH}_{2}$ destabilization and shortening of hydrogen diffusion paths ${ }^{22,23}$.

Mechanical milling of magnesium or magnesium hydride with transition metals leads to the formation of nanocomposite (NC) materials with excellent hydrogen sorption kinetics ${ }^{24-26}$. Indeed, reaction kinetics are particularly enhanced by addition of Early Transition Metals (ETM) 
belonging to the groups 3 to 5 and periods 4 and 5 of the periodic table; i.e. $E T M=\mathrm{Sc}, \mathrm{Y}, \mathrm{Ti}, \mathrm{Zr}, \mathrm{Y}$ and $\mathrm{Nb}$. All these metals have the ability to form stable hydrides at normal conditions of pressure and temperature ${ }^{27}$. Hydrogen storage properties of nanocomposites NCs made of $\mathrm{MgH}_{2}$ and ETM hydrides are widely reported in the literature ${ }^{28-33}$ but comparative studies between them to provide new insights on their role on the sorption properties are still lacking.

In this work, a systematic and comparative study of the hydrogenation properties of $\mathrm{MgH}_{2}-E T M \mathrm{H}_{x}$ nanocomposites $(E T M=\mathrm{Sc}, \mathrm{Y}, \mathrm{Ti}, \mathrm{Zr}, \mathrm{V}$, and $\mathrm{Nb}$ ) is provided. The atomic ratio Mg:ETM has been fixed to $95: 5$ based on previous publications showing fast reaction kinetics for different systems ${ }^{34-36}$. NCs have been synthetized under identical conditions by reactive ball milling (RBM) under hydrogen atmosphere ${ }^{21}$ to get equivalent microstructural properties. Key hydrogenation properties of these NCs (namely H-thermodynamics, H-kinetics and $\mathrm{H}$-cycling) have been determined with the aim to clarify and to gain a better understanding of ETM effects on the hydrogenation properties of the $\mathrm{Mg}-\mathrm{H}$ system.

\section{Experimental}

$\mathrm{MgH}_{2}-E T M \mathrm{H}_{x}$ nanocomposites were synthetized by RBM of five grams of powder mixtures containing $\mathrm{Mg}$ and ETM metals $(E T M=\mathrm{Y}, \mathrm{Ti}, \mathrm{Zr}, \mathrm{V}$, and $\mathrm{Nb})$. Mg:ETM atomic ratio was fixed to 95:5. Origin, particle size and purity (metal basis) of metals are the following: Mg (Alfa Aesar <800 $\mu \mathrm{m}, 99.8 \%$ ), $\mathrm{Y}$ (Stream Chemicals, $<400 \mu \mathrm{m}, 99.9 \%$ ), Ti (Aldrich, <44 $\mu \mathrm{m}, 99.9 \%$ ), $\mathrm{Zr}$ (Cerac, $<44 \mu \mathrm{m}, 99.7 \%$ ), V (Stream Chemicals, $<44 \mu \mathrm{m}, 99.5 \%$ ), $\mathrm{Nb}$ (Chem Pur, <100 $\mu \mathrm{m}, 99.9 \%$ ). Sc was purchased to China Rare Metals (99.9 \%) in the form of millimeter-size lumps. To transform Sc lumps into micrometric powder, Sc was hydrogenated at $473{ }^{\circ} \mathrm{C}$ under $\mathrm{P}_{\mathrm{H} 2}=1 \mathrm{MPa}$. Such $\mathrm{ScH}_{2}$ powder was used as reactant of RBM process. RBM of 95Mg-5ETM powder mixtures under hydrogen gas ( $6 \mathrm{~N}$ Alphagaz) was performed in a high-pressure milling vial (Evicomagnetics, Germany) equipped with both gas pressure and temperature sensors ${ }^{37}$. RBM of additive-free $\mathrm{Mg}$ powder was also done for comparison purposes. The commercial vial was connected to a manometric hydrogenation device equipped with calibrated volumes. Using this device, we established the starting hydrogen pressure in the vial (typically $8 \mathrm{MPa}$ ) and determined the volume occupied by the gas in the vial (typically $166 \mathrm{~cm}^{3}$ ). Monitored vial temperatures were below 59C. The milling process was performed in a Fritsch Pulverisette 4 planetary mill at disk and vial rotation speed of $400 \mathrm{rpm}$ and $-800 \mathrm{rpm}$ (relative to disk), respectively, with a ball-to-powder mass ratio of 60:1. Stainless steel balls of $12 \mathrm{~mm}$ in diameter were used. Milling was carried out in two cycles, 120 min milling time and 120 min rest each. An experimental procedure described in a previous publication allows for determining the hydrogen uptake with a typical error less than $5 \%{ }^{38}$. The samples were fully hydrogenated during the first cycle. Final pressure at this stage is typically $6 \mathrm{MPa}$. The second cycle, showing no further hydrogen uptake, was used for calibration.

After the RBM, the pressure in the milling vial was released to $\mathrm{P}_{\mathrm{H} 2} \sim 0.1 \mathrm{MPa}$ and the sample was then recovered in a glove box under argon atmosphere for microstructural analysis and determination of hydrogenation properties. The structural properties of the as-milled NCs were characterized by X-ray diffraction (XRD) with a Bruker D8 Advance diffractometer (Cu $K \alpha_{1,2}$ radiation) in a $2 \theta$ range from 25 to $75^{\circ}$. A special airtight sample-holder was used to avoid air exposure. Phase analysis and structural determination of NCs were determined by the full-profile fitting software Fullprof ${ }^{39}$ based on Rietveld's method ${ }^{40,41}$. Morphological characterization of NCs was done by Scanning Electron Microscopy (SEM) in back-scattered electron (BSE) mode using a Merlin-Zeiss SEM apparatus. The NCs powders were deposited over a black conducting carbon adhesive tape.

$\mathrm{H}$-Thermodynamic properties of $\mathrm{MgH}_{2}-E T M \mathrm{H}_{x}$ nanocomposites were determined through the acquisition of both absorption and desorption Pressure-Composition Isotherms (PCl) at $573 \mathrm{~K}$ using a home-made Sieverts' manometric device ${ }^{42}$. Isothermal sorption kinetics measurements were performed at $573 \mathrm{~K}$ in the same system at quasi-constant pressure using large reservoirs. NCs were first heated up from room temperature (RT) to $573 \mathrm{~K}$ under $\mathrm{P}_{\mathrm{H} 2}=1 \mathrm{MPa}$ to avoid any hydrogen release. Then, isothermal desorption and absorption hydrogenation curves at $573 \mathrm{~K}$ were monitored by fixing the sorption pressure to 0.03 and 0.8 $\mathrm{MPa}$, respectively. Those pressures were chosen to provide equivalent driving force for desorption and absorption: $\ln \left(P_{p} / P_{\text {des }}\right)=\ln \left(P_{a b s} / P_{p}\right) \approx 1.6$, taking into consideration that the equilibrium plateau pressure $\left(P_{p}\right)$ of the $\mathrm{Mg} / \mathrm{MgH}_{2}$ system is $0.16 \mathrm{MPa}$ at $573 \mathrm{~K}^{43}$. Sorption time was constrained to 15 min., compatible with the characteristic time needed for refilling hydrogen storage tanks ${ }^{44}$. Sorption curves and the related $\mathrm{H}$-reversible capacities $\left(C_{\text {rev }}\right)$ were measured over 20 cycles. The structural properties of the cycled NCs were characterized by X-ray diffraction (XRD) and analyzed by the Rietveld's method as described before. 


\section{ARTICLE}
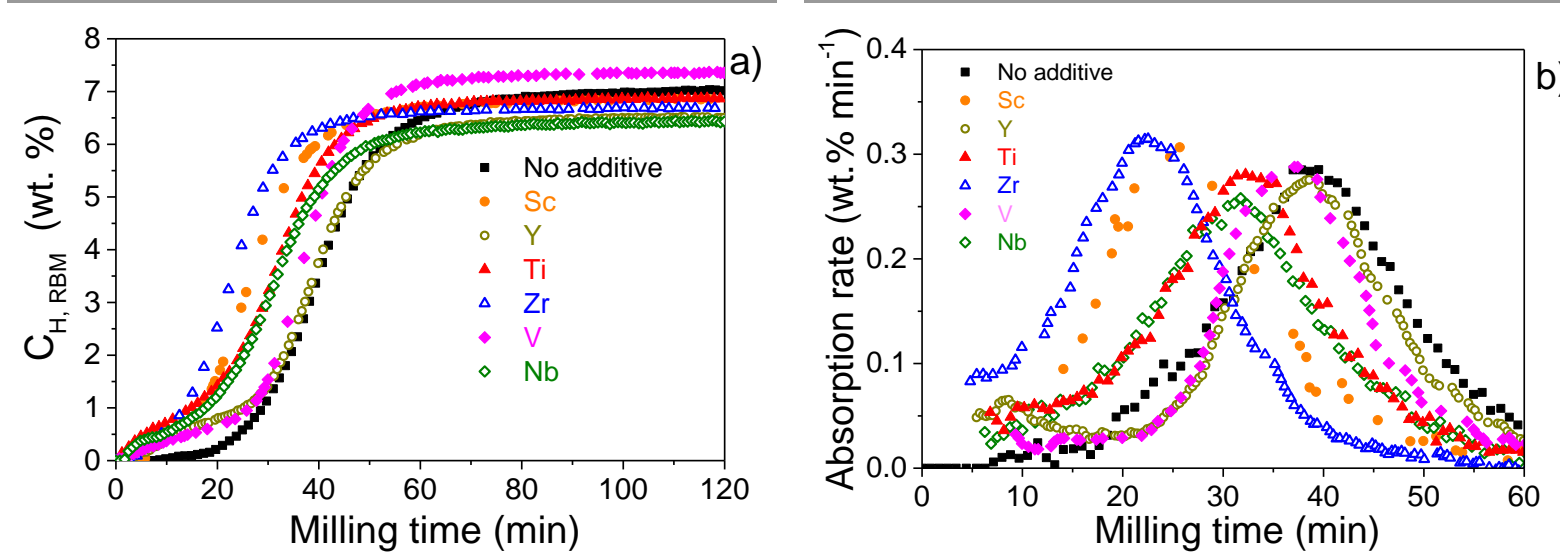

Figure 1. a) Hydrogen uptake curves of $95 \mathrm{Mg}-5 E T M$ powder mixtures during RBM synthesis and b) the corresponding absorption rates (derivative curves of Fig. 1a)

Table 1. Nominal composition, nominal hydrogen content $\left(C_{H, \text { Nominal }}\right)$, measured hydrogen uptake by $\mathrm{RBM}\left(\mathrm{C}_{H, R B M}\right)$ and $\mathrm{RBM}$ reaction yield of $95 \mathrm{Mg} \mathrm{H}_{2}-5 E T M \mathrm{H}_{\times}$ nanocomposites. Experimental uncertainties referring to the last digit are given in parenthesis

\begin{tabular}{|c|c|c|c|} 
Additive & Nominal NC Composition & $C_{H, \text { Nominal }}$ (wt.\%) & $C_{H, R B M}$ (wt.\%) \\
\hline $\mathrm{Sc}$ & $95 \mathrm{MgH}_{2}-5 \mathrm{ScH}_{2}$ & 7.4 & $6.8(4)$ \\
$\mathrm{Y}$ & $95 \mathrm{MgH}_{2}-5 \mathrm{YH}_{3}$ & 6.8 & $6.5(3)$ \\
$\mathrm{Ti}$ & $95 \mathrm{MgH}_{2}-5 \mathrm{TiH}_{2}$ & 7.3 & $6.7(4)$ \\
$\mathrm{Zr}$ & $95 \mathrm{MgH}_{2}-5 \mathrm{ZrH}_{2}$ & 6.8 & $6.9(4)$ \\
$\mathrm{V}$ & $95 \mathrm{MgH}_{2}-5 \mathrm{VH}_{2}$ & 7.3 & $7.3(4)$ \\
$\mathrm{Nb}$ & $95 \mathrm{MgH}_{2}-5 \mathrm{NbH}_{2}$ & 6.8 & $6.4(3)$ \\
No additive & $\mathrm{MgH}_{2}$ & 7.6 & $7.1(4)$
\end{tabular}

* Reaction yield calculated as $100 C_{H, R B M} / C_{H}$, Nominal. For Sc, the use of $\mathrm{ScH}_{2}$ as initial reactant is considered.

\section{Results}

\section{Synthesis and microstructural characterization of $\mathrm{MgH}_{2}-\mathrm{ETMH}_{x}$ nanocomposites.}

Figure 1 shows the hydrogen uptake curves and the corresponding absorption rates during the RBM synthesis of $\mathrm{MgH}_{2}-E T M \mathrm{H}_{x}$ nanocomposites as well as for the additive-free $\mathrm{MgH}_{2}$. In all cases, full reaction takes place in less than 120 min. As gathered in Table 1 , the total hydrogen uptake determined by RBM is $\geq 6.4$ wt.\%, which corresponds to a reaction yield above $90 \%$ considering the expected formation of $\mathrm{MgH}_{2}-E T M \mathrm{H}_{x}$ nanocomposites with $x=2$ for $E T M=\mathrm{Sc}, \mathrm{Ti}, \mathrm{Zr}$, $\mathrm{V}, \mathrm{Nb}$ and $x=3$ for $E T M=\mathrm{Y}$. Indeed, at the used RBM conditions $\left(\mathrm{P}_{\mathrm{H} 2} \sim 8 \mathrm{MPa}, \mathrm{T} \sim \mathrm{RT}\right)$ all studied ETMs but $\mathrm{Y}$ form dihydride compounds. For $\mathrm{Y}$, the formation of $\mathrm{YH}_{3}$ is reported 27. The hydrogen uptake curve for additive-free $\mathrm{MgH}_{2}$ has a sigmoidal shape. When using ETM additives, a shoulder is observed at short milling time, $t_{m} \leq 15 \mathrm{~min}$, which is assigned to the formation of the ETM hydride ${ }^{28}$. At longer milling time, $t_{m} \geq 15 \mathrm{~min}, \mathrm{MgH}_{2}$ formation takes place at a rate which depends on the nature of the additive. As displayed in Fig. 1b, the hydrogen absorption rate, which is proportional to the rate of $\mathrm{MgH}_{2}$ formation, increases along the sequence $\mathrm{Y}<\mathrm{V}<\mathrm{Ti}<$ $\mathrm{Nb}<\mathrm{Sc}<\mathrm{Zr}$.

Figure 2 displays the XRD patterns of as-milled RBM samples. All patterns exhibit broad diffraction peaks evidencing nanostructured materials with main contribution of the two $\mathrm{MgH}_{2}$ polymorphs: rutile-type $\beta-\mathrm{MgH}_{2}$ (space group, S.G. $\left.=P 4_{2} / \mathrm{mnm}\right)$ and orthorhombic $\gamma-\mathrm{MgH}_{2}($ S.G. $=P b c n)$, a metastable high-pressure phase commonly found in grinded $\mathrm{MgH}_{2}{ }^{45}$. When using ETM, additional hydride phases are observed: $\delta-\mathrm{ScH}_{2}$ (S.G. $F m-3 m$ ), $\varepsilon-\mathrm{YH}_{3}$ (S.G. P-3c1), $\varepsilon-\mathrm{TiH}_{2}$ (S.G. $14 / \mathrm{mmm}$ ), $\varepsilon-\mathrm{ZrH}_{2}$ (S.G. $14 / \mathrm{mmm}$ ), $\beta_{2}$-VH (S.G. $\left.14 / \mathrm{mmm}\right)^{46}$ and 
coexistence of monohydride $\beta-\mathrm{NbH}$ (S.G. Pnnn) ${ }^{47}$ and dihydride $\delta-\mathrm{NbH}_{2}$ (S.G. $F m-3 m$ ) for $E T M=\mathrm{Sc}, \mathrm{Y}, \mathrm{Ti}, \mathrm{Zr}, \mathrm{V}, \mathrm{Nb}$, respectively. Except for $\mathrm{V}$ and $\mathrm{Nb}$, all $E T M \mathrm{H}_{x}$ correspond to fully hydrogenated compounds, i.e. di-hydride for Sc, Ti and $\mathrm{Zr}$ and tri-hydride for $\mathrm{Y}$. In contrast, for $\mathrm{V}$ and $\mathrm{Nb}$, mono-hydride phases, instead of fully hydrogenated di-hydride ones, are detected. Indeed, for $\mathrm{V}$ and $\mathrm{Nb}$, the equilibrium plateau pressure of the monohydride to dihydride transformation is slightly above atmospheric pressure at room temperature ${ }^{48}$. The plateau pressure is lower for $\mathrm{NbH}_{2}$ to $\mathrm{NbH}$ transformation than for the $\mathrm{V}$ case. Thus, since the vial pressure is decreased to atmospheric value before XRD measurements, dihydrides of $\mathrm{V}$ and $\mathrm{Nb}$ tend to transform (fully for $\mathrm{V}$ and partially for $\mathrm{Nb}$ ) to the monohydride ones.

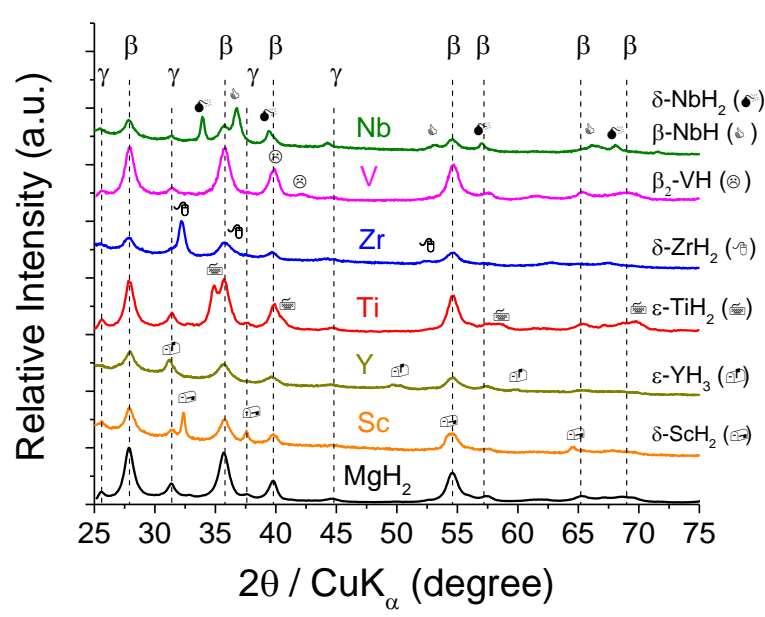

Figure 2. XRD patterns of $95 \mathrm{MgH}_{2}+E T M \mathrm{H}_{x}$ nanocomposites after RBM synthesis. Diffraction peaks from $\beta$ - and $\gamma-\mathrm{MgH}_{2}$ phases are marked with vertical lines. Diffraction peaks of $E T M H_{x}$ phases are marked with symbols. 
Table 2. Crystallographic data for $95 \mathrm{MgH}_{2}-5 E T M \mathrm{H}_{x} \mathrm{RBM}$ nanocomposites. Detected phases, space group (S.G.), cell parameters, crystallite size ( $L$ ) and Rietveld reliability factors $\left(R_{B}, R_{w p}\right)$ are given. Standard deviations referring to the last digit are given in parenthesis.

\begin{tabular}{|c|c|c|c|c|c|c|c|c|c|}
\hline \multirow{2}{*}{ Additive } & \multirow{2}{*}{ Phase } & \multirow{2}{*}{$\begin{array}{l}\text { Content } \\
\text { (wt.\%) }\end{array}$} & \multirow{2}{*}{ S.G. } & \multicolumn{3}{|c|}{ Cell parameters } & \multirow{2}{*}{$\begin{array}{c}L \\
(\mathrm{~nm})\end{array}$} & \multirow{2}{*}{$\begin{array}{l}R_{B} \\
(\%)\end{array}$} & \multirow{2}{*}{$\begin{array}{l}R_{w p} \\
\text { (\%) }\end{array}$} \\
\hline & & & & $a(\AA ̊)$ & $b(\AA ̊)$ & $c(\AA)$ & & & \\
\hline \multirow{3}{*}{ Sc } & $\mathrm{ScH}_{2}$ & 9(1) & $F m-3 m$ & $4.790(1)$ & - & - & $31(5)$ & 4.4 & \multirow{3}{*}{3.1} \\
\hline & $\beta-\mathrm{MgH}_{2}$ & $69(2)$ & $\mathrm{PL}_{2} / \mathrm{mnm}$ & $4.519(1)$ & - & $3.025(1)$ & $7(1)$ & 8.7 & \\
\hline & $\gamma-\mathrm{MgH}_{2}$ & $22(2)$ & Pbcn & $4.535(3)$ & $5.414(3)$ & $4.958(3)$ & $7(1)$ & 1.9 & \\
\hline \multirow{3}{*}{$Y$} & $\mathrm{YH}_{3}$ & $5(1)$ & $P-3 c 1$ & $6.366(1)$ & - & $6.646(2)$ & $11(2)$ & 5.9 & \multirow{3}{*}{2.3} \\
\hline & $\beta-\mathrm{MgH}_{2}$ & $68(2)$ & $P 4_{2} / m n m$ & $4.521(1)$ & - & $3.035(1)$ & $6(1)$ & 2.4 & \\
\hline & $\gamma-\mathrm{MgH}_{2}$ & $27(2)$ & Pbcn & $4.571(3)$ & $5.452(3)$ & $4.964(3)$ & $6(1)$ & 5.9 & \\
\hline \multirow{3}{*}{$\mathrm{Ti}$} & $\varepsilon-\mathrm{TiH}_{2}$ & 10(1) & $14 / \mathrm{mmm}$ & $3.173(1)$ & - & $4.403(1)$ & 10(1) & 5.7 & \multirow{3}{*}{9.8} \\
\hline & $\beta-\mathrm{MgH}_{2}$ & $69(3)$ & $P 4_{2} / m n m$ & $4.516(1)$ & - & $3.027(1)$ & $6(1)$ & 2.5 & \\
\hline & $\gamma-\mathrm{MgH}_{2}$ & $21(2)$ & Pbcn & $4.528(4)$ & $5.427(4)$ & $4.959(3)$ & $6(1)$ & 9.2 & \\
\hline \multirow{3}{*}{$\mathrm{Zr}$} & $\varepsilon-\mathrm{ZrH}_{2}$ & $17(1)$ & $14 / \mathrm{mmm}$ & $3.489(1)$ & - & $4.558(2)$ & 10(1) & 7.9 & \multirow{3}{*}{4.2} \\
\hline & $\beta-\mathrm{MgH}_{2}$ & $63(2)$ & $P 4_{2} / m n m$ & $4.542(1)$ & - & $3.028(1)$ & $6(1)$ & 5.1 & \\
\hline & $\gamma-\mathrm{MgH}_{2}$ & $21(2)$ & Pbcn & $4.542^{*}$ & $5.422 *$ & 4.966* & $6(1)$ & 13.4 & \\
\hline \multirow{3}{*}{ V } & $\beta_{2}-\mathrm{VH}$ & $7(1)$ & $14 / \mathrm{mmm}$ & $3.039(1)$ & - & $3.390(2)$ & $7(1)$ & 2.5 & \multirow{3}{*}{8.1} \\
\hline & $\beta-\mathrm{MgH}_{2}$ & $80(2)$ & $P 4_{2} / m n m$ & $4.519(1)$ & - & $3.021(1)$ & $7(1)$ & 3.8 & \\
\hline & $\gamma-\mathrm{MgH}_{2}$ & $13(1)$ & Pbcn & $4.540(4)$ & $5.405(5)$ & $4.967(4)$ & $7(1)$ & 6.7 & \\
\hline \multirow{4}{*}{$\mathrm{Nb}$} & $\delta-\mathrm{NbH}_{2}$ & $7(1)$ & $F m-3 m$ & $4.565(1)$ & - & - & $17(2)$ & 3.9 & \multirow{4}{*}{3.3} \\
\hline & $\beta-\mathrm{NbH}$ & $10(1)$ & Pnnn & $3.457(1)$ & $4.906(1)$ & $4.831(1)$ & $17(2)$ & 2.1 & \\
\hline & $\beta-\mathrm{MgH}_{2}$ & $62(2)$ & $P 4_{2} / m n m$ & $4.518(1)$ & - & $3.017(1)$ & $7(1)$ & 2.5 & \\
\hline & $\gamma-\mathrm{MgH}_{2}$ & $21(2)$ & Pbcn & $4.529(5)$ & $5.423(7)$ & $5.010(5)$ & $7(1)$ & 7.1 & \\
\hline \multirow{2}{*}{ No additive } & $\beta-\mathrm{MgH}_{2}$ & $78(2)$ & $P 4_{2} / m n m$ & $4.526(1)$ & - & $3.027(1)$ & $7(1)$ & 2 & \multirow{2}{*}{8.3} \\
\hline & $\gamma-\mathrm{MgH}_{2}$ & $22(2)$ & Pbcn & $4.542(3)$ & $5.422(3)$ & $4.966(3)$ & $7(1)$ & 8 & \\
\hline
\end{tabular}

* Values were fixed to ensure refinement convergence.

All diffraction patterns were analyzed by the Rietveld method ${ }^{26}$. The graphical output is displayed in Fig. S1 (Electronic Supplementary Information, ESI) and crystal data are gathered in Table 2. The cell parameters of the two $\mathrm{MgH}_{2}$ polymorphs and their relative content $\left(24 \pm 3 \mathrm{wt} . \%\right.$ of $\left.\gamma-\mathrm{MgH}_{2}\right)$ are not significantly affected by ETM addition. The former observation suggests that there is no major solubility of ETM in the $\mathrm{MgH}_{2}$ phases. The content of $E T M \mathrm{H}_{x}$ phases is $~ 9 \mathrm{wt} . \%$ and $\sim 17$ wt.\% for metals of periods 4 and 5, respectively. Considering the different masses of the ETMs, this concurs with the nominal atomic ratio of the NCs (i.e. 95Mg:5ETM); showing additional evidence of no formation of ternary $\mathrm{Mg}$ -
ETM-H phases. The only exception to this general rule is the case of $\mathrm{Y}$, for which only 5 wt.\% of $\mathrm{YH}_{3}$ (instead of nominal 16 wt.\%) is detected. This may indicate inhomogeneous distribution of $\mathrm{YH}_{3}$ (i.e. low $\mathrm{YH}_{3}$ concentration at $\mathrm{MgH}_{2}-\mathrm{YH}_{3} \mathrm{NCs}$ surface) or partial $\mathrm{YH}_{3}$ amorphization. The crystal size of all detected phases, $L$, determined from the width of diffraction peaks after instrumental correction ${ }^{26}$, is in the low nanometric range: $7 \mathrm{~nm}$ for $\mathrm{MgH}_{2}$ phases and comprised between 7 and $17 \mathrm{~nm}$ for $E T M H_{x}$ phases. The crystal size for $\mathrm{ScH}_{2}$ is significantly larger (31 $\pm 5 \mathrm{~nm})$, which may result from the different preparation route for this hydride. 


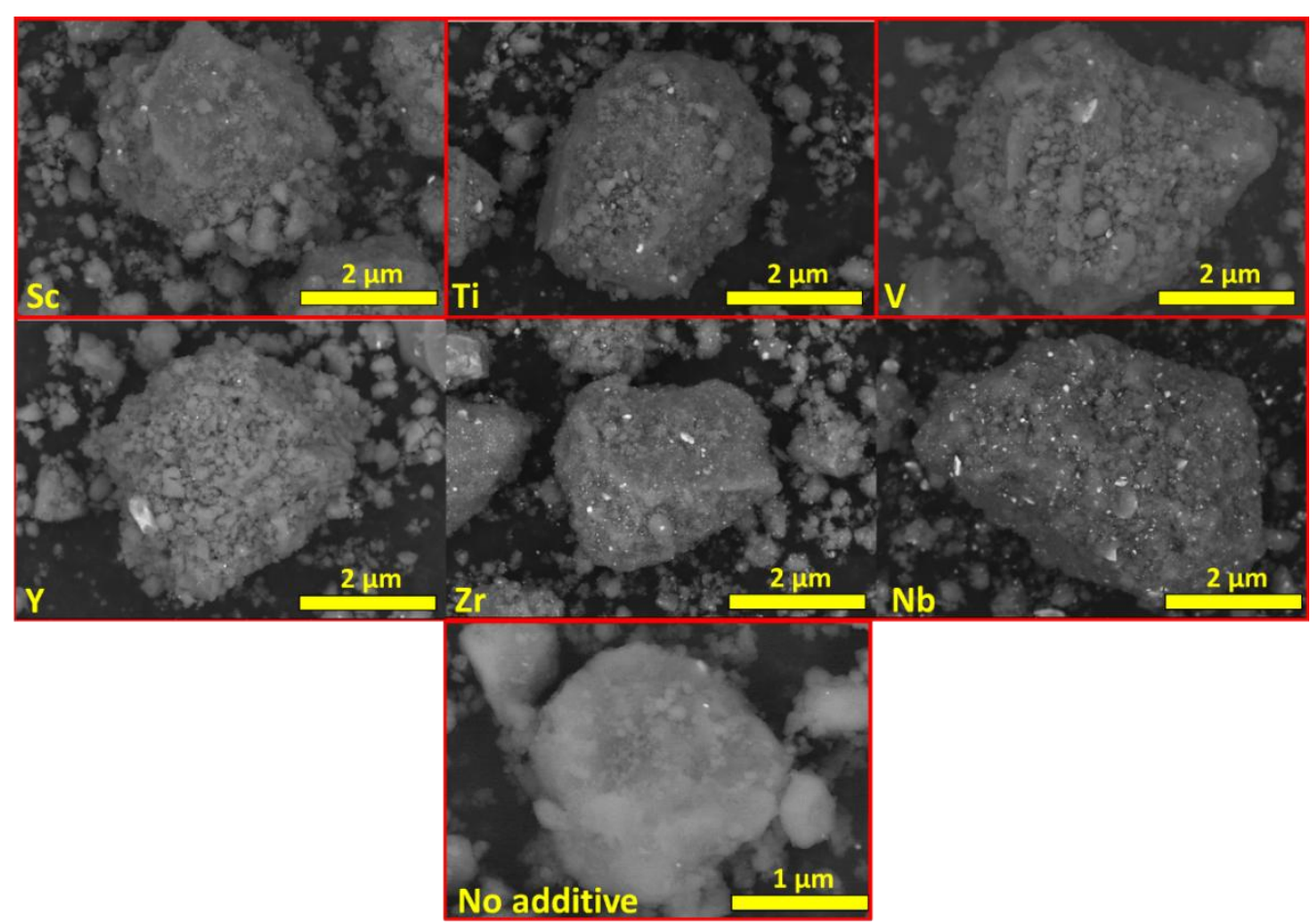

Figure 3. SEM images in BSE mode of hydrogenated $\mathrm{MgH}_{2}-E T M H_{x}$ powders after RBM synthesis

SEM images in BSE mode of as-synthesized $\mathrm{MgH}_{2}-\mathrm{ETMH}_{x}$ $\mathrm{NCs}$, as well as for the $\mathrm{MgH}_{2}$ sample without additive, are shown in Figure 3. All samples consist of micrometric agglomerates (size $\sim 2 \mu \mathrm{m}$ ) formed by $\sim 20 \mathrm{~nm}$ in size primary particles. Homogeneously distributed tiny white dots are observed in all SEM images. These white dots reveal the presence of phases with higher electronic density as compared to the main constituent $\mathrm{MgH}_{2}$. They are clearly observed for $\mathrm{Ti}$, $\mathrm{Zr}, \mathrm{V}$ and $\mathrm{Nb}$ and in less extent for Sc and $\mathrm{Y}$. They are assigned to the corresponding $E T M H_{x}$ hydrides. These hydrides are homogenously dispersed all over the $\mathrm{MgH}_{2}$ matrix in agreement with previous RBM studies performed for the $\mathrm{MgH}_{2}-\mathrm{TiH}_{2}$ system ${ }^{49,50}$.

\section{Hydrogen sorption properties.}

$\mathrm{H}$-Thermodynamics. $\mathrm{PCl}$ measurements at $573 \mathrm{~K}$ within the pressure range $10^{-2}$ to $1 \mathrm{MPa}$ were carried out for all NCs and are shown in Figure 4. Both absorption (Fig. 4a) and desorption (Fig. 4b) data show flat plateau pressures $P_{\mathrm{p}}$ at values close to those reported for the binary $\mathrm{Mg}-\mathrm{H}$ system. Therefore, thermodynamic properties of the $\mathrm{Mg}-\mathrm{H}$ system are not significantly modified by the presence of $E T M H_{x}$ hydrides. At low pressure, $\mathrm{P}_{\mathrm{H} 2} \leq 0.01 \mathrm{MPa}$, a low hydrogen amount, between 0.3 and 0.5 wt.\%, is trapped in the NCs. It is attributed to irreversible hydrogen stored in $E T M H_{x}$ hydrides. At the measured conditions, Sc, $\mathrm{Ti}$ and $\mathrm{Zr}$ form stable dihydride phases, $\mathrm{Y}$ forms tri-hydride $\mathrm{YH}_{3}$, while hydrogen content in $\mathrm{VH}_{x}$ and $\mathrm{NbH}_{\mathrm{x}}$ phases slightly varies between $x \sim 0.3$ and $0.8^{28}$. $\mathrm{YH}_{3}$ decomposes into $\mathrm{YH}_{2}$ at $\sim 0.01 \mathrm{MPa}{ }^{51}$. 

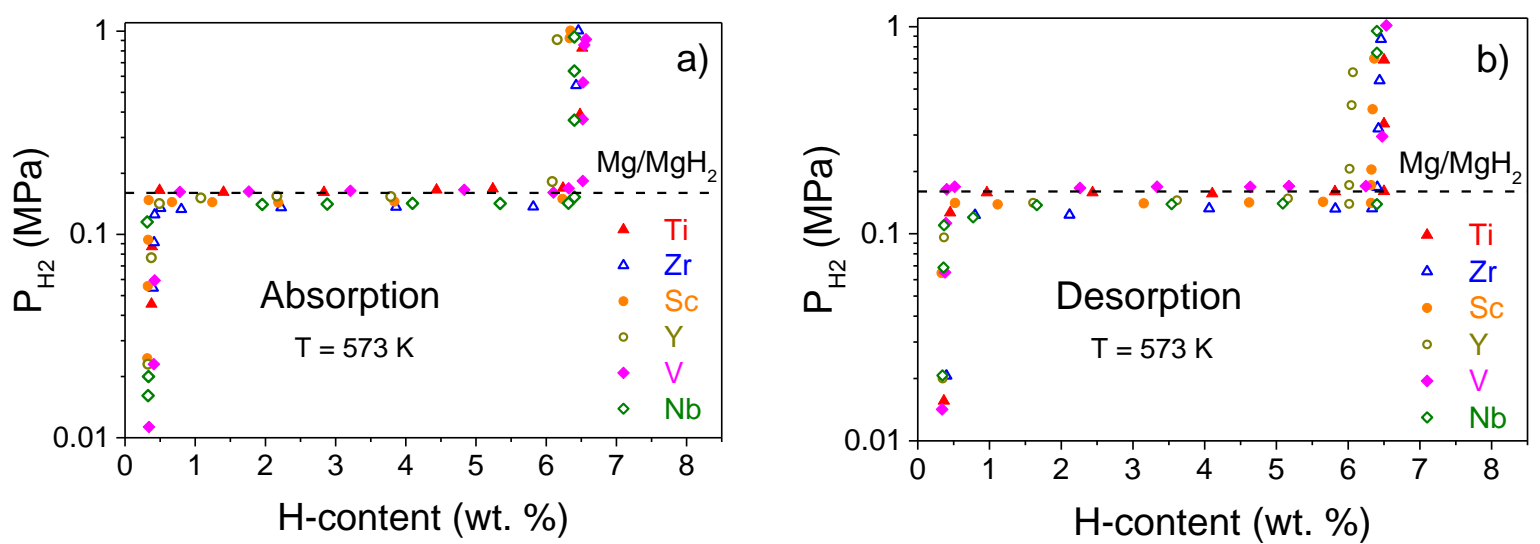

Figure 4. $\mathrm{PCl}$ curves at $573 \mathrm{~K}$ of $\mathrm{MgH}_{2}-E T M \mathrm{H}_{\mathrm{x}} \mathrm{NCs}$. a) absorption, b) desorption. Expected plateau pressure for $\mathrm{Mg} / \mathrm{MgH} \mathrm{H}_{2}$ transformation, $P_{\mathrm{P}}(573 \mathrm{~K})=0.16 \mathrm{MPa}$, is depicted by a dashed line.

Hydrogen kinetics and cycling. Figure 5 shows the hydrogen sorption curves at $573 \mathrm{~K}$ of $\mathrm{MgH}_{2}-E T M \mathrm{H}_{x} \mathrm{NCs}$ and their evolution on cycling for selected sorption sweeps. The RBM synthesis is considered as the first absorption reaction. Within the studied pressure window $\left(\mathrm{P}_{\mathrm{H} 2}(\mathrm{abs})=0.8 \mathrm{MPa}\right.$, $\mathrm{P}_{\mathrm{H} 2}($ des $\left.)=0.03 \mathrm{MPa}\right), \mathrm{H}$-sorption curves refer to the reversible $\mathrm{MgH}_{2} / \mathrm{Mg}$ transformation as derived from PCl data (Fig. 4).

Desorption curves for all NCs are essentially linear at short reaction time. On the first cycle, desorption rates increase as $Y$ $<\mathrm{Sc}<\mathrm{Ti}<\mathrm{Zr} \sim \mathrm{Nb} \sim \mathrm{V}$. Yttrium additive hardly accelerates desorption kinetics of $\mathrm{MgH}_{2}$. Desorption rate for $\mathrm{Y}$ is $0.06 \mathrm{wt} . \%$ $\mathrm{min}^{-1}$ leading to $1 \mathrm{wt} \%$ of hydrogen release after $15 \mathrm{~min}$. At the opposite, $\mathrm{V}$ additive provides the fastest kinetics with initial desorption rate of $3 \mathrm{wt} . \% \mathrm{~min}^{-1}$ and total hydrogen release after $15 \mathrm{~min}$ of reaction of $6.1 \mathrm{wt} \%$, which represents $90 \%$ of the hydrogen stored in the $\mathrm{MgH}_{2}$ counterpart of the $\mathrm{MgH}_{2}-\mathrm{VH}$ nanocomposite. The $2^{\text {nd }}$ desorption sweep displays similar features, except for Sc and Ti curves which have faster kinetics as compared to the $1^{\text {st }}$ desorption sweep. This enhancement is particularly significant for Ti additive, with initial desorption rate of $3 \mathrm{wt} . \% \mathrm{~min}^{-1}$ and total $\mathrm{H}$-release of $5.2 \mathrm{wt} . \%$. These trends are confirmed on further cycling (see desorption sweep at the $20^{\text {th }}$ cycle) with enhanced rates for $\mathrm{Sc}$, while $\mathrm{Ti}, \mathrm{Zr}, \mathrm{Nb}$ and $\mathrm{V}$ additives provide fast and similar kinetics. For additives of groups 4 and 5, the total hydrogen release at cycle 20 is attained in less than $5 \mathrm{~min}$. In addition, it is worth noting that for $\mathrm{Ti}$ the total hydrogen release is rather stable on cycling $(5.2$ and $4.8 \mathrm{wt} . \%$ at cycles 2 and 20) whereas it decreases significantly for $\mathrm{Zr}, \mathrm{Nb}$ and $\mathrm{V}$ additives.

Absorption curves for all NCs follow deceleratory functions which are typical of diffusion-controlled reactions ${ }^{52}$. Reaction rate for $Y$ is sluggish as for desorption. It improves to a certain extent for Sc and much more for ETMs of groups 4 and 5 whose absorption curves deserve detailed description. For these NCs, very fast absorption rates (over $10 \mathrm{wt} . \% \mathrm{~min}^{-1}$ ) are monitored in the $2^{\text {nd }}$ sweep at short reaction time, followed by a drastic slowing down of kinetics at long reaction time. Indeed, absorption curves can be described as a two-step reaction process with fast (first step) and slow (second step) reaction kinetics. The relative contributions of these two steps changes on cycling. Taking $E T M s=\mathrm{Zr}$ as an example, it absorbs at the $2^{\text {nd }}$ cycle 4.8 and $0.2 \mathrm{wt} \%$ within the first and next 14 minutes, respectively, whereas, at the $20^{\text {th }}$ cycle, it absorbs 2.5 and $0.9 \mathrm{wt} \%$ under the same periods of time. Thus, for ETMs of groups 4 and 5, the extent of the $\mathrm{Mg}$ to $\mathrm{MgH}_{2}$ reacted fraction that quickly absorbs hydrogen within the first step gradually decreases on cycling, while that of the second step, with slower kinetics, increases on cycling. Interestingly, this evolution is less pronounced for ETMs = Ti, whose absorption kinetics remain rather stable on cycling. As a final remark, hydrogen uptake in a given cycle is observed to be slightly but systematically lower than hydrogen release in the previous one. This indicates that the absorption sweep is limiting as compared to the desorption one. 

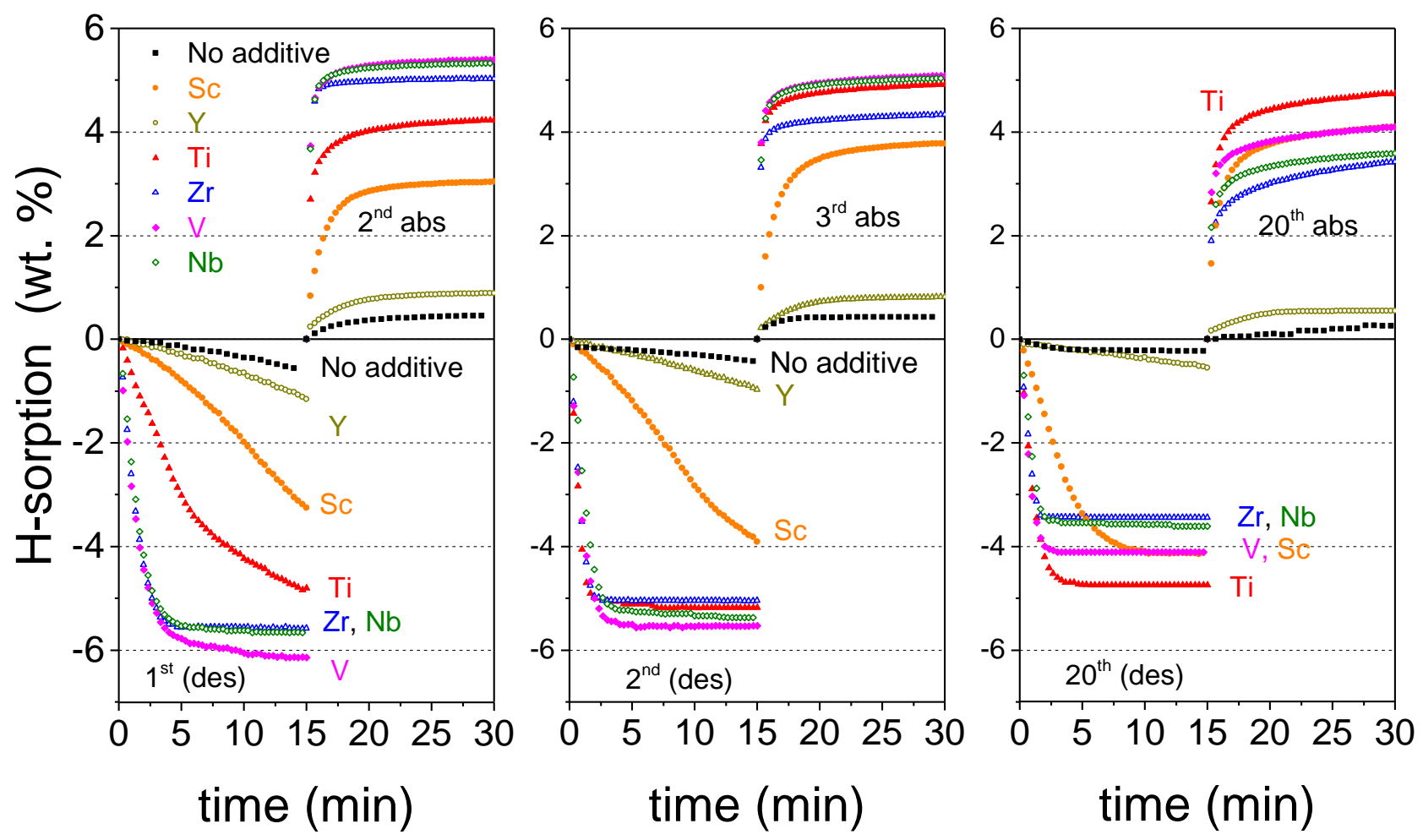

Figure 5. Hydrogen sorption curves at $573 \mathrm{~K}$ of $\mathrm{MgH}_{2}-E T M \mathrm{H}_{\mathrm{x}} \mathrm{NCs}$ for different sorption sweeps. Absorption and desorption hydrogen pressures fixed to 0.8 and $0.03 \mathrm{MPa}$, respectively. Sorption time limited to $15 \mathrm{~min}$.

For each hydrogenation cycle, the reversible hydrogen capacity $C_{\text {rev }}$ of $\mathrm{MgH}_{2}-E T M \mathrm{H}_{x} \mathrm{NCs}$ has been determined from the cycling sorption curves (Figure 5 ) and is depicted in Figure 6. Four different trends can be distinguished. For $Y$, the reversible capacity is very low (1 wt.\%) from the first cycle, being only slightly better than additive-free $\mathrm{MgH}_{2}$ (0.6 wt.\%). It results from the very sluggish reaction kinetics on desorption for both materials. For Sc, an activation-like behavior is observed. It starts at low $C_{\text {rev }}$ (3.2 wt.\%), increases up to a maximum (4.8 wt.\%) after 7 cycles and then gradually decreases down (4.1 wt.\%) upon long-cycling. This activation feature results from the enhancement of desorption kinetics for Sc on cycling (Figure 5). For $\mathrm{Zr}$-, Nb- and V-containing NCs, high $C_{r e v}$ (between 5.6 and $6.1 \mathrm{wt} . \%$ ) are obtained at the first cycle but gradually decrease on cycling (between 3.5 and 4.1 wt\% at cycle 20). This decay is assigned to the slowing down of absorption kinetics on cycling for these NCs. Finally, Ti provides the most stable cycling behavior with the best reversible capacity (4.8 wt.\%) remaining stable upon 20 cycles. This performance results from fast desorption kinetics as well as stable absorption kinetics on cycling.

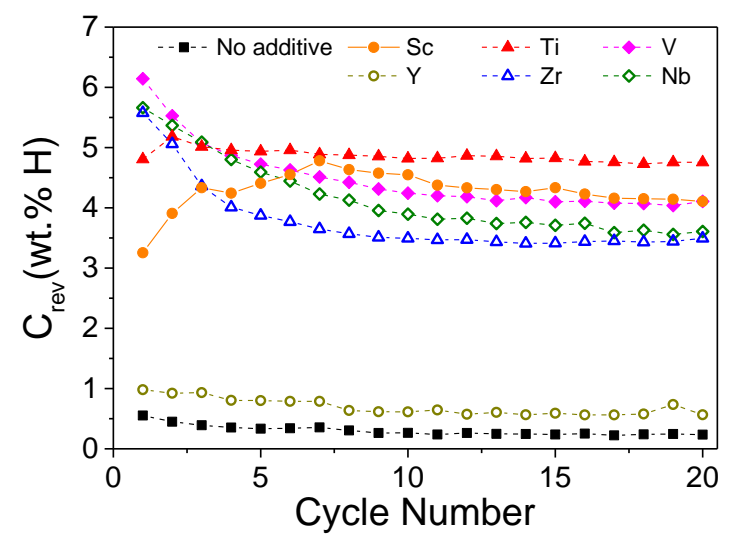

Figure 6. Evolution of the reversible capacity on cycling of $\mathrm{MgH}_{2}-E_{M} M \mathrm{H}_{\mathrm{x}}$ nanocomposites 


\section{Discussion}

In most cases, formation of $\mathrm{MgH}_{2}$ by RBM is accelerated by the presence of ETM additives (Fig. 1). This enhancement can be assigned either to surface effects, i.e. catalytic dissociation of hydrogen molecules at the surface of $E T M H_{x}$ nanoparticles, or to bulk effects such as favoured $\mathrm{MgH}_{2}$ nucleation at $\mathrm{Mg} / E T M \mathrm{H}_{x}$ interfaces. Yttrium, which is hydrogenated as $\mathrm{YH}_{3}$ in the early state of milling, is an exception to this general rule. $\mathrm{MgH}_{2}$ rate formation during RBM is poorly affected by $\mathrm{YH}_{3}$. The origin of this will be later discussed when analysing the hydrogen properties of $\mathrm{MgH}_{2}-\mathrm{YH}_{3}$ nanocomposite.

Whatever the ETM used, microstructural properties of the as-synthetized materials are very similar. They form two-phase nanocomposites made of $\mathrm{MgH}_{2}$ and $E T M \mathrm{H}_{x}$. In all cases, $\mathrm{MgH}_{2}$ crystallizes with the coexistence of $\beta$-rutile and $\gamma$-metastable polymorphic forms in weight ratio $76: 24 \mathrm{wt} \%$ and crystallite size of $\sim 7 \mathrm{~nm}$ (Table 2). Moreover, $\mathrm{MgH}_{2}-E^{2} \mathrm{MH}_{x}$ nanocomposites form micrometric agglomerates $\sim 2 \mu \mathrm{m}$ in size (Fig.3). Such microstructural properties are typical for $\mathrm{MgH}_{2}$ materials synthetized by mechanochemistry of $\mathrm{Mg}$ under hydrogen atmosphere as well as by mechanical milling of $\mathrm{MgH}_{2}$ under argon ${ }^{53}$.

The thermodynamic properties of the $\mathrm{Mg}-\mathrm{H}$ system at 573 $\mathrm{K}$ are not modified in RBM nanocomposites by the presence of $E T M H_{x}$ phases (Fig. 4). Indeed, the crystallite size of $\mathrm{MgH}_{2}$ is too large and $\mathrm{MgH}_{2} /$ ETMH $_{\mathrm{x}}$ interface-energy contribution is too low to give rise to any significant thermodynamic change in the $\mathrm{Mg}-\mathrm{H}_{2}$ solid-gas reaction ${ }^{22,30,54,55}$. It is worth noting that formation of ternary Mg-ETM-H phases has not been detected. If that had happened, thermodynamic modifications would have been observed as it occurs for Mg-based complex hydrides incorporating late transition metals (e.g. $\left.\mathrm{Mg}_{2} \mathrm{NiH}_{4}\right)^{56}$. Although the microstructural properties of all nanocomposites are alike, and the thermodynamic properties of the $\mathrm{Mg}-\mathrm{H}$ system are not modified by the presence of $E T M H_{x}$, the $\mathrm{H}$ kinetics (Fig. 5) and $\mathrm{H}$-cycling (Fig. 6) properties of $\mathrm{MgH}_{2}-$ $E T M H_{x}$ nanocomposites strongly depend on the nature of the additive. In other words, the ETMs do play a key role in the transport of hydrogen in $\mathrm{MgH}_{2}-E T M \mathrm{H}_{x}$ nanocomposites but not in thermodynamics.

To gain a better understanding on the additive role, as displayed in Figure 7, the hydrogen content in the nanocomposites after each sorption sweep was evaluated and assigned to each phase. The initial $\mathrm{H}$-content was fixed to the nominal capacity of the nanocomposite (Table 1) and then, desorbed and absorbed hydrogen amounts at each cycle sweep (Fig. 5) were considered to determine $\mathrm{H}$-contents. This allows to estimate the amount of retained $\mathrm{MgH}_{2}$ (i.e. nondesorbed magnesium hydride) at the end of desorption sweeps as well as the amount of unreacted $\mathrm{Mg}$ (i.e. nonhydrogenated $\mathrm{Mg}$ ) for absorption ones (respectively top and bottom hatched areas in Figure 7). The irreversible hydrogen content stored in the form of thermodynamically stable $E T M H_{x}$ phases (grey area at bottom of Fig. 7) is also represented. In this way, the white area located between the upper and lower hatched ones gives a clear picture of the available reversible capacity $C_{r e v}$ for the $\mathrm{MgH}_{2}-E T M \mathrm{H}_{\mathrm{x}}$ nanocomposites upon cycling.
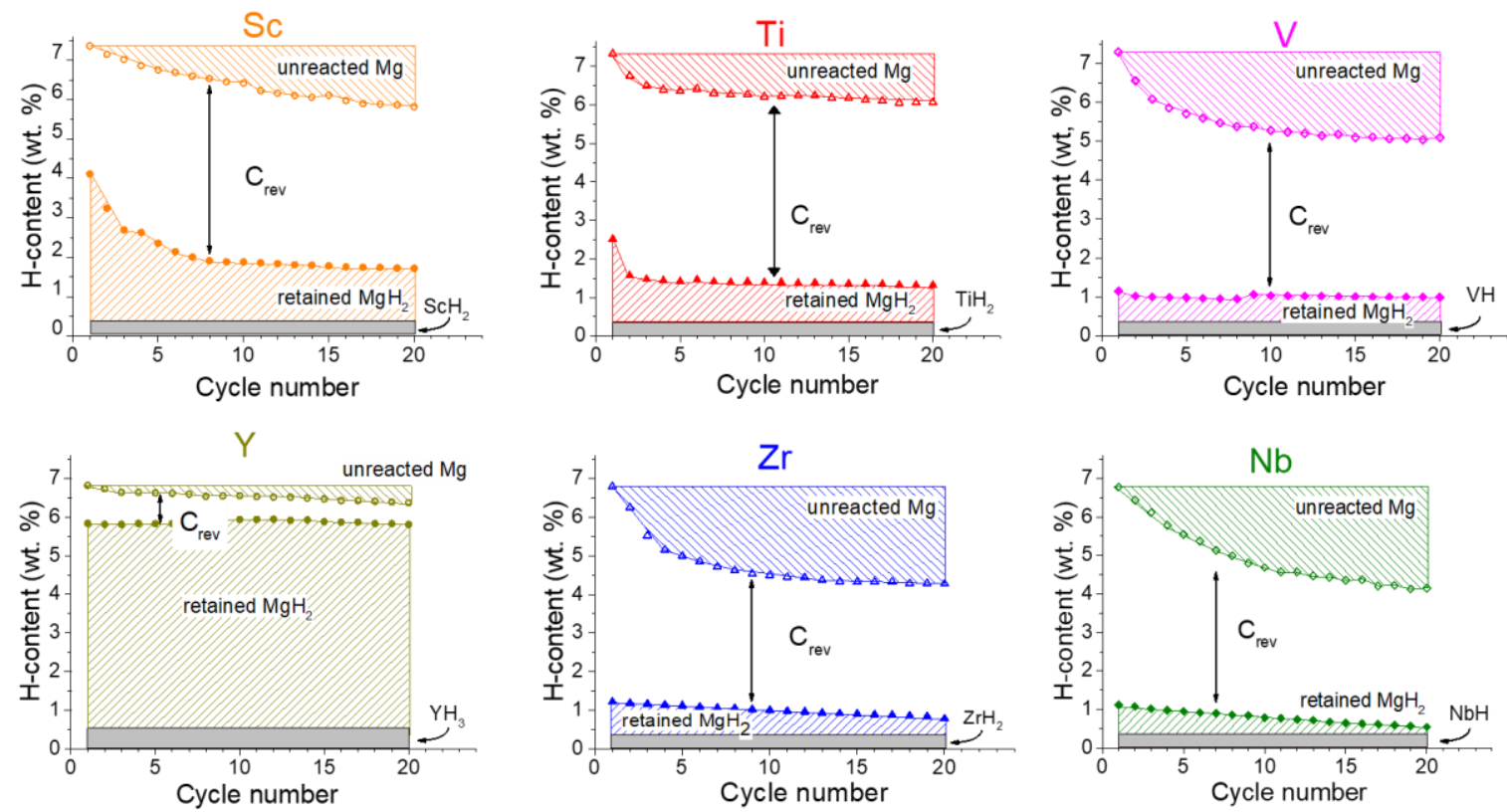

Figure 7. $\mathrm{H}$-content in $\mathrm{MgH}_{2}-E T M \mathrm{H}_{\mathrm{x}}$ nanocomposites for subsequent desorption (full symbols) and absorption (empty symbols) sweeps. Hatched areas stand for retained $\mathrm{MgH}$ and unreacted $\mathrm{Mg}$ at each sorption sweep, respectively. Hydrogen stored in ETMHx hydrides is displayed in grey at the bottom. The white area located between the upper and lower hatched ones gives the reversible capacity $C_{\text {rev }}$ 
The evolution of $\mathrm{H}$-content in the $\mathrm{Y}$-containing nanocomposite clearly differs from other NCs. The amount of retained $\mathrm{MgH}_{2}$ is dramatically high from the first desorption sweep and remains practically unchanged on cycling. Indeed, the $\mathrm{H}$-desorption kinetics of $\mathrm{MgH}_{2}-\mathrm{YH}_{3}$ nanocomposite is almost as sluggish as that of $\mathrm{RBM} \mathrm{MgH}_{2}$ (Fig. 5). Such a slow kinetics concurs with the lack of influence of $\mathrm{YH}_{3}$ in the formation kinetics of $\mathrm{MgH}_{2}$ by RBM (Fig. 1) pointing to the fact that the efficiency of $\mathrm{YH}_{3}$ to transport hydrogen from the gas phase to $\mathrm{Mg}$ and from $\mathrm{MgH}_{2}$ to the gas phase is very low. This cannot be attributed to sluggish diffusivity of hydrogen in yttrium hydrides. As a matter of fact, yttrium films used in switchable mirrors (which are based on the metal to semiconductor phase transition between $\mathrm{YH}_{2}$ and $\mathrm{YH}_{3}$ ) exhibit fast $\mathrm{H}$-uptake even at room temperature ${ }^{57}$. Therefore, poor $\mathrm{H}$ transport at $\mathrm{YH}_{3}$ surface or $\mathrm{YH}_{3} / \mathrm{MgH}_{2}$ interfaces should be at the origin of sluggish kinetics in $\mathrm{MgH}_{2}-\mathrm{YH}_{3}$ nanocomposite. As concerns surface reactions, the electronic structure of the host metal is of paramount importance to dissociate or recombine hydrogen molecules at metal surfaces with low energy barrier 58. Indeed, whereas $\mathrm{H}_{2}$-surface reactions are difficult on $\mathrm{Mg}$, early and late transition metals (characterized by empty and filled $d$-bands, respectively) are good surface catalysts 6,59,60 The Fermi level of early and late transition metals is thus located around s-type orbitals, which is a necessary condition to promote $\mathrm{H}_{2}$ surface reactions ${ }^{58}$. In contrast, $\mathrm{MgH}_{2}$ and $\mathrm{YH}_{3}$ hydrides, being both semiconductors with no available electronic states at the Fermi level ${ }^{61}$, have little catalytic activity towards $\mathrm{H}_{2}$ surface reactions. Indeed, in switchable mirrors this issue is overcome by covering yttrium films with a $\mathrm{Pd}$ overlayer that ensures $\mathrm{H}_{2}$ dissociation and recombination ${ }^{62}$. Thus, we propose that both additive-free $\mathrm{RBM} \mathrm{MgH}_{2}$ and $\mathrm{MgH}_{2}-\mathrm{YH}_{3}$ nanocomposites exhibit sluggish desorption kinetics as result of poor recombination of hydrogen atoms into molecules at the surface.

Metallic hydrides from other early transition metals $\left(\mathrm{ScH}_{2}\right.$, $\mathrm{TiH}_{2}, \mathrm{ZrH}_{2}, \mathrm{VH}$ and $\mathrm{NbH}$ ) are characterized by partially occupied $d$-bands near the Fermi level ${ }^{63,64}$ that facilitate $\mathrm{H}_{2}$-surface reactions. For instance, it has been experimentally demonstrated that $\mathrm{TiH}_{1.95}$ hydride can easily dissociate and recombine hydrogen molecules at room temperature ${ }^{65}$. In this work, their use as additives clearly enhances the $\mathrm{H}$-desorption rate of $\mathrm{MgH}_{2}$ from the first cycle (Fig. 5) and leads to minor $\mathrm{MgH}_{2}$ retention on cycling (Fig. 7). One may however argue that this improvement is less effective for Sc-additive which has moderate desorption kinetics (Fig. 5) and keeps significant amount of retained $\mathrm{MgH}_{2}$ on cycling (Fig. 7). In addition, $\mathrm{MgH}_{2}$ $\mathrm{ScH}_{2}$ has a unique activation behaviour on cycling (Fig. 6). The peculiar $\mathrm{H}$-properties of $\mathrm{MgH}_{2}-\mathrm{ScH}_{2} \mathrm{NC}$ can be assigned to the singular conditions of $\mathrm{MgH}_{2}-\mathrm{ScH}_{2}$ synthesis for which scandium hydride, and not scandium metal, was used as RBM reactant. As a matter of fact, the crystallite size of this hydride $(L \sim 30$ $\mathrm{nm}$ ) after RBM is much larger for Sc than for the other ETMHX additives. This suggests that crystallite size as well as the nature of $\mathrm{MgH}_{2} / E T M H x$ interfaces depend on the nanocomposite preparation route and influence its hydrogenation kinetics.

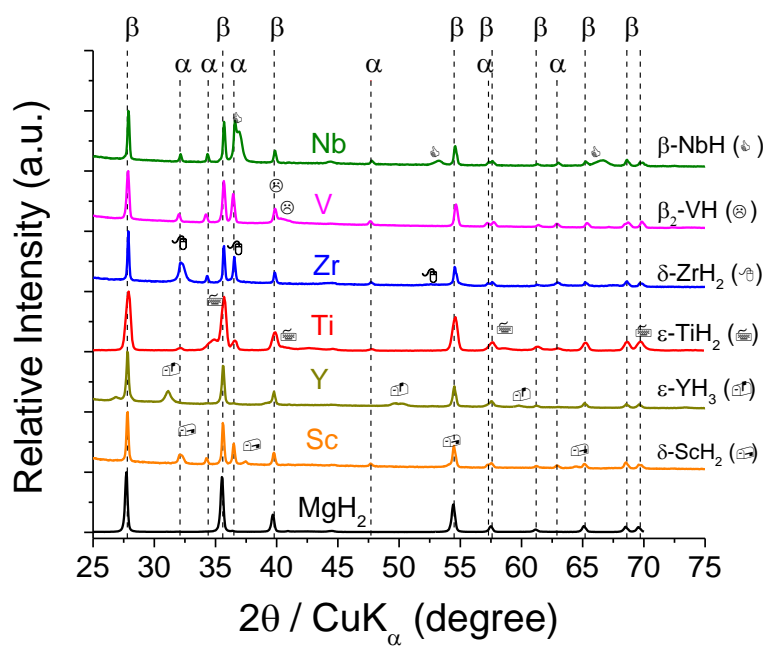

Figure 8. XRD patterns of $95 \mathrm{MgH}_{2}+E T M \mathrm{H}_{x}$ nanocomposites after the $20^{\text {th }}$ absorption sweep. Diffraction peaks from $\alpha-\mathrm{Mg}$ and $\beta-\mathrm{MgH}_{2}$ phases are marked by vertical lines. Diffraction peaks of $E T M H_{x}$ phases are marked by symbols.

Let's focus now on the $\mathrm{H}$-properties of ETMs belonging to groups $4\left(\mathrm{Ti}\right.$ and $\mathrm{Zr}$ ) and $5(\mathrm{~V}$ and $\mathrm{Nb})$. All related $\mathrm{MgH}_{2}-E T M \mathrm{H}_{x}$ nanocomposites exhibit very fast desorption kinetics (Fig. 5), $C_{\text {rev }}$ being limited by absorption ones. Absorption kinetics are characterized by a two-step reaction process, which is commonly attributed to fast and multiple formation of $\mathrm{MgH}_{2}$ nuclei at defects (first stage) that grow and build-up a $\mathrm{MgH}_{2}$ layer through which hydrogen diffusion ${ }^{53,66}$ is very slow (second stage). As shown in Fig. 5, the kinetics of the second stage slows down on cycling, especially for $\mathrm{Zr}, \mathrm{V}$ and $\mathrm{Nb}$. Consequently, the amount of unreacted $\mathrm{Mg}$ gradually increases on cycling (Fig. 7) and the reversible hydrogen capacities steadily decrease (Fig. 6). One may hypothesize that slowing down of absorption kinetics is due to the enlargement of the $\mathrm{MgH}_{2}$ layer as result of significant crystallite growth upon hydrogen absorption and desorption.

To verify this hypothesis, X-ray diffraction analysis have been performed on cycled samples after the $20^{\text {th }}$ absorption sweep. XRD patterns are shown in Figure 8, the graphical output of Rietveld analysis is given in Figure S2 (ESI) and obtained crystallographic data are gathered in Table 3. As compared to the XRD patterns of as-synthetized NCs (Figure $2)$, main changes upon cycling concern the disappearance of $y$ $\mathrm{MgH}_{2}$ phase -a fact widely reported in literature- ${ }^{50,53}$, the formation of $\alpha-\mathrm{Mg}$ and the sharpening of $\beta-\mathrm{MgH}_{2}$ diffraction peaks. Structural properties of $E T M H_{x}$ hydrides are not significantly affected by $\mathrm{H}$-cycling. They behave as catalysts. Ticontaining $\mathrm{NC}$ exhibits the largest broadening for $\beta-\mathrm{MgH}_{2}$ diffraction peaks. Indeed, for Ti-containing NC crystallite size of $\beta-\mathrm{MgH}_{2}$ remains small after cycling, $L_{\mathrm{MgH} 2}=24 \pm 2 \mathrm{~nm}$, whereas 
it increases quite significantly for other ETMs such as $\mathrm{Nb}$ $\left(L_{\mathrm{MgH} 2}=100 \pm 10 \mathrm{~nm}\right)$ and $\mathrm{Zr}\left(L_{\mathrm{MgH} 2}=160 \pm 20 \mathrm{~nm}\right)$. For $Y$ containing and additive-free samples, which hardly desorb hydrogen, the crystal size only enlarges moderately $\left(L_{\mathrm{MgH} 2} \sim 50 \mathrm{~nm}\right)$ suggesting that crystal growth occurs preferentially after $\mathrm{MgH}_{2}$ decomposition, i.e. in the $\mathrm{Mg}$ phase.
It should be noted that the amount of unreacted $\mathrm{Mg}$ is high (above 20 wt.\%), for ETM = Sc, Zr, V and Nb, whereas it is low, $7 \pm 1$ wt.\%, for Ti-containing NC. Unreacted $\mathrm{Mg}$ amount concurs with $\mathrm{H}$-content analysis in the NCs (Figure 7).

Table 3. Crystallographic data for $95 \mathrm{MgH}_{2}-5 E T M \mathrm{H}_{x} \mathrm{RBM}$ nanocomposites after the $20^{\text {th }}$ absorption sweep. Detected phases, space group (S.G.), cell parameters, crystallite size ( $L$ ) and Rietveld relaibility factors $\left(R_{B}, R_{w p}\right)$ are given. Standard deviations referring to the last digit are given in parenthesis.

\begin{tabular}{|c|c|c|c|c|c|c|c|c|c|}
\hline \multirow{2}{*}{ Additive } & \multirow{2}{*}{ Phase } & \multirow{2}{*}{$\begin{array}{l}\text { Content } \\
\text { (wt.\%) }\end{array}$} & \multirow{2}{*}{ S.G. } & \multicolumn{3}{|c|}{ Cell parameters } & \multirow{2}{*}{$\begin{array}{c}L \\
(\mathrm{~nm})\end{array}$} & \multirow{2}{*}{$\begin{array}{l}R_{B} \\
(\%)\end{array}$} & \multirow{2}{*}{$\begin{array}{l}R_{w p} \\
(\%)\end{array}$} \\
\hline & & & & $a(\AA)$ & $b(\AA)$ & $c(\AA ̊)$ & & & \\
\hline \multirow{3}{*}{ Sc } & $\delta-\mathrm{ScH}_{2}$ & $10(1)$ & $F m-3 m$ & 4.791(1) & - & - & & 2.8 & \multirow{3}{*}{3.} \\
\hline & $\beta-\mathrm{MgH}_{2}$ & $69(2)$ & $P 4_{2} / m n m$ & $4.521(1)$ & - & $3.024(1)$ & $82(7)$ & 3.5 & \\
\hline & $\mathrm{Mg}$ & & $P 6_{3} / m m c$ & $3.213(1)$ & - & $5.217(1)$ & $83(11)$ & 2.8 & \\
\hline \multirow{3}{*}{$Y$} & $\varepsilon-\mathrm{YH}_{3}$ & $14(1)$ & $P-3 c 1$ & $6.355(1)$ & - & $6.611(1)$ & $13(1)$ & 3.5 & \multirow{3}{*}{3.1} \\
\hline & $\beta-\mathrm{MgH}_{2}$ & $85(1)$ & $P 4_{2} / m n m$ & $4.520(1)$ & - & $3.023(1)$ & $54(2)$ & 1.9 & \\
\hline & $\mathrm{Mg}$ & $1(1)$ & $P 6_{3} / m m c$ & $3.210^{*}$ & - & $5.215^{*}$ & $54^{*}$ & 19 & \\
\hline \multirow{3}{*}{$\mathrm{Ti}$} & $\varepsilon-\mathrm{TiH}_{2}$ & 9(1) & $14 / \mathrm{mmm}$ & $3.166(2)$ & - & $4.407(4)$ & 9(3) & 12.6 & \multirow{3}{*}{20} \\
\hline & $\beta-\mathrm{MgH}_{2}$ & $84(2)$ & $P 4_{2} / m n m$ & $4.521(1)$ & - & $3.024(1)$ & $24(2)$ & 5.5 & \\
\hline & $\mathrm{Mg}$ & & $P 6_{3} / m m c$ & $3.213(1)$ & - & $5.215(3)$ & $24(3)$ & 25 & \\
\hline \multirow{3}{*}{$\mathrm{Zr}$} & $\varepsilon-\mathrm{ZrH}_{2}$ & $18(1)$ & $14 / \mathrm{mmm}$ & $3.479(1)$ & - & $4.575(1)$ & $11(1)$ & 7.8 & \multirow{3}{*}{5} \\
\hline & $\beta-\mathrm{MgH}_{2}$ & $61(1)$ & $P 4_{2} / m n m$ & $4.519(1)$ & - & $3.022(1)$ & $160(20)$ & 4.8 & \\
\hline & $\mathrm{Mg}$ & & $P 6_{3} / m m c$ & $3.214(1)$ & - & $5.220(1)$ & $240(50)$ & 7.4 & \\
\hline \multirow{3}{*}{ V } & $\beta_{2}-\mathrm{VH}$ & $8(1)$ & $14 / \mathrm{mmm}$ & $3.119(1)$ & - & $3.186(2)$ & $7(2)$ & 2.7 & \multirow{3}{*}{3.3} \\
\hline & $\beta-\mathrm{MgH}_{2}$ & $65(1)$ & $P 4_{2} / m n m$ & $4.504(1)$ & - & $3.014(1)$ & $52(2)$ & 0.9 & \\
\hline & $\mathrm{Mg}$ & & $P 6_{3} / m m c$ & $3.212(1)$ & - & $5.215(1)$ & $56(5)$ & 2.4 & \\
\hline \multirow{3}{*}{$\mathrm{Nb}$} & $\beta-\mathrm{NbH}$ & $17(1)$ & Pnnn & $3.433(1)$ & $4.905(1)$ & $4.844(1)$ & $17(2)$ & 1.4 & \multirow{3}{*}{3.9} \\
\hline & $\beta-\mathrm{MgH}_{2}$ & $58(1)$ & $P 4_{2} / m n m$ & $4.519(1)$ & - & $3.022(1)$ & $100(10)$ & 5.3 & \\
\hline & $\mathrm{Mg}$ & & $P 6_{3} / m m c$ & $3.211(1)$ & - & $5.215(1)$ & $103(15)$ & 6.9 & \\
\hline \multirow{2}{*}{ No additive } & $\beta-\mathrm{MgH}_{2}$ & 99(1) & $P 4_{2} / m n m$ & $4.520(1)$ & - & $3.023(1)$ & $49(1)$ & 6.1 & \multirow{2}{*}{13} \\
\hline & $\mathrm{Mg}$ & $1(1)$ & $P 6_{3} / m m c$ & $3.210^{*}$ & - & $5.215^{*}$ & $49 *$ & 24 & \\
\hline
\end{tabular}

* Values were fixed to ensure refinement convergence.

Figure 9 shows the extent of the $\mathrm{Mg}$ to $\mathrm{MgH}_{2}$ reacted fraction, $F$ (in \%), for $\mathrm{MgH}_{2}-E T M H x$ nanocomposites at the $20^{\text {th }}$ absorption sweep as a function of the $\mathrm{MgH}_{2}$ crystal size $L_{\mathrm{MgH} 2}$, both $F$ and $L_{\mathrm{MgH} 2}$ being obtained from the Rietveld analysis of XRD data. As a general trend, it is clearly observed that the lower the crystal size, the higher the reacted fraction. It confirms that Ti-additive is the most efficient ETM to minimize $\mathrm{MgH}_{2}$ crystal growth and thereby it keeps fast absorption kinetics on cycling and maximize the extent of the $\mathrm{Mg}$ to $\mathrm{MgH}_{2}$ phase transformation. The fact that $\mathrm{TiH}_{2}$ is the best grain growth inhibitor can be tentatively attributed to coherent coupling between $\mathrm{Mg}$ and $\mathrm{TiH}_{2}$ thanks to their close molar volume, $V_{m}=13.8$ and $13.2 \mathrm{~cm}^{3}$, respectively ${ }^{50,54,67}$. Molar volume of all $E T M H_{x}$ hydrides here studied and their comparison with those of $\mathrm{Mg}$ and $\mathrm{MgH}_{2}$ are given in Table S1 (ESI). 


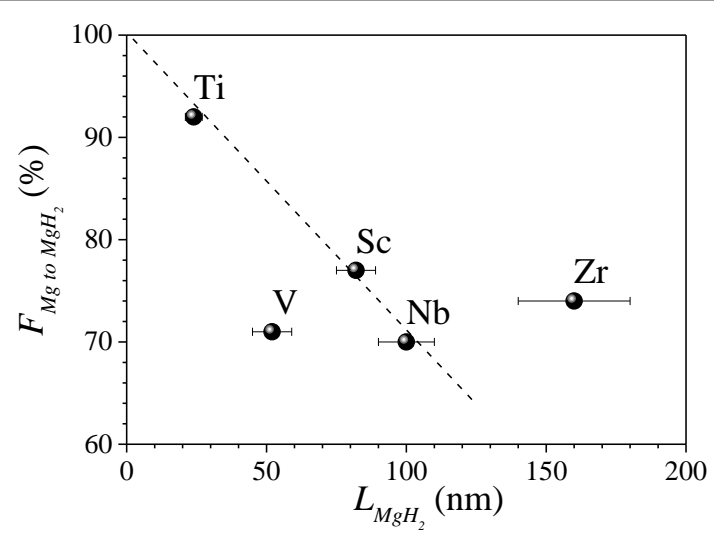

Figure 9. Dependence of the $\mathrm{Mg}$ to $\mathrm{MgH}_{2}$ reacted fraction, $F$, on the $\mathrm{MgH}_{2}$ crystallite size $L_{M g H}$ for $\mathrm{MgH}_{2}-E T M H_{x}$ nanocomposites at the $20^{\text {th }}$ absorption sweep. The dashed line is a guide to the eye.

A more critical analysis of Fig. 9 shows that some additives deviate from a linear correlation between $F$ and $L_{M g H 2}$ suggesting that besides crystal size other factors play a role on the extent of the $\mathrm{Mg}$ to $\mathrm{MgH}_{2}$ reaction $F$. Indeed, $\mathrm{F}$ is higher than expected for $\mathrm{Zr}$-additive, whereas is lower for $\mathrm{V}$-one. This scales with the relative difference in molar volume between the nucleating $\mathrm{MgH}_{2}$ phase and $E T M \mathrm{H}_{x}$ hydrides $\Delta V_{m} / V_{m, M g H 2}$ (Table S1). This difference is the lowest for $\mathrm{Zr}$-additive, $11 \%$, while it is the highest for $\mathrm{V}, 93 \%$. Then, it can be reasonably proposed that $\mathrm{MgH}_{2}$ preferentially nucleates at $E T M H_{x} / \mathrm{Mg}$ interfaces and that the energy barrier for nucleation decreases by lowering the molar volume difference between the nucleating $\mathrm{MgH}_{2}$ phase and $E T M \mathrm{H}_{x}$ hydrides. Thus, $\mathrm{MgH}_{2}$ nucleation energy barrier is much lower for $\mathrm{Zr}$ than for $\mathrm{V}$. This observation also concurs with the fact that kinetics of $\mathrm{MgH}_{2}$ formation by RBM (Fig. 1) is the fastest for $\mathrm{Zr}$ and the slowest for $V$ (excluding the peculiar case of $Y$ which suffers from additional surface barriers).

\section{Conclusions}

Reactive ball milling under hydrogen gas is an efficient method for the synthesis of nanostructured $\mathrm{MgH}_{2}$ powders intimately mixed with hydrides of early transition metals of groups 3 to 5 . $\mathrm{MgH}_{2}-E T M \mathrm{H}_{x}$ nanocomposites consist of $\sim 2 \mu \mathrm{m}$ in size agglomerates formed by primary crystallite particles of $\sim 20 \mathrm{~nm}$ in size. The $\mathrm{H}$-thermodynamics of the $\mathrm{Mg}-\mathrm{H}$ system are not significantly affected by the presence of $E T M H_{x}$ as no ternary Mg-ETM-H phases are formed and phase domains are too large to induce size-effects. In contrast, all studied $E T M H_{x}$ but $\mathrm{YH}_{3}$ strongly enhance hydrogen absorption and desorption kinetics of the $\mathrm{Mg}-\mathrm{H}$ system.

The role of $E T M \mathrm{Hx}$ as catalysts of $\mathrm{H}$-kinetics in $\mathrm{Mg}$ has been elucidated from conjoint analysis of $\mathrm{H}$-sorption curves, evolution of $\mathrm{H}$-content on cycling, and structural data. It is schematically depicted in Figure 10 for the absorption case. Compared to $\mathrm{Mg}$ metal, dissociation of molecular hydrogen into $\mathrm{H}$-atoms (step 1 ) is favored by the presence of $E T M H_{x}$ hydrides thanks to the availability of $s$-type orbitals around the Fermi level. Note that this also applies for the reversible reaction, i.e. $\mathrm{H}_{2}$ recombination. Next, hydrogen atoms can diffuse extremely fast in $E T M H_{x}$ hydrides (step 2), having a diffusion coefficient five orders of magnitude higher than in $\mathrm{MgH}_{2}{ }^{10,68,69}$. Thus, $\mathrm{H}$-atoms are quickly transferred to the $E T M H_{x} / M g$ interface where $\mathrm{MgH}_{2}$ easy nucleates when a suitable lattice mismatch exists between the molar volumes of $E T M H_{x}$ and $\mathrm{MgH}_{2}$ phases (step 3). Moreover, structural coupling at $E T M H_{x} / M g$ interfaces minimizes $\mathrm{Mg}$ grain growth on cycling and provides structural stability as well as reversible hydrogen uptake. This occurs particularly for $\mathrm{TiH}_{2}$, with a molar volume almost identical to $\mathrm{Mg}$. Consequently, $\mathrm{TiH}_{2}$ offers the best hydrogenation properties in terms of reversible capacity and cycling stability of all $E T M H_{x}$ here studied. Outstanding kinetic and cycling properties of $\mathrm{MgH}_{2}-\mathrm{TiH}_{2}$ nanocomposites have been highlighted in many recent reports $12,28,30,36,50,70-74$. At the operation conditions used in the present study, a stable reversible capacity of $4.8 \mathrm{wt}$.\% over 20 cycles is obtained for reaction time limited to $15 \mathrm{~min}$. Further studies will be necessary for a deep characterization of $\mathrm{MgH}_{2} / E T M \mathrm{H}_{\mathrm{x}}$ interfaces as well as for long-term cycling (over hundreds to thousands of cycles) of these nanocomposite materials. The use of high-resolution techniques and spectroscopic methods for fine microstructural analysis, particularly of interfaces, will be required for this task. Previous works demonstrate that Transmission Electron Microscopy and neutron diffraction analysis are of particular interest for microstructural characterization ${ }^{50,75}$, while MAS ${ }^{2} \mathrm{H}$ Nuclear Magnetic Resonance is well-suited to characterize hydrogen mobility and lattice coupling at $\mathrm{MgH}_{2} / E T M \mathrm{H}_{\mathrm{x}}$ interfaces ${ }^{76,77}$. Moreover, severe microstructural modifications, including migration of $E T M \mathrm{H}_{\mathrm{x}}$ catalysts, may occur upon long-term cycling, which can be properly characterized by conjoint X-Ray Photoelectron Spectrometry and Microscopy studies ${ }^{50,75,78}$

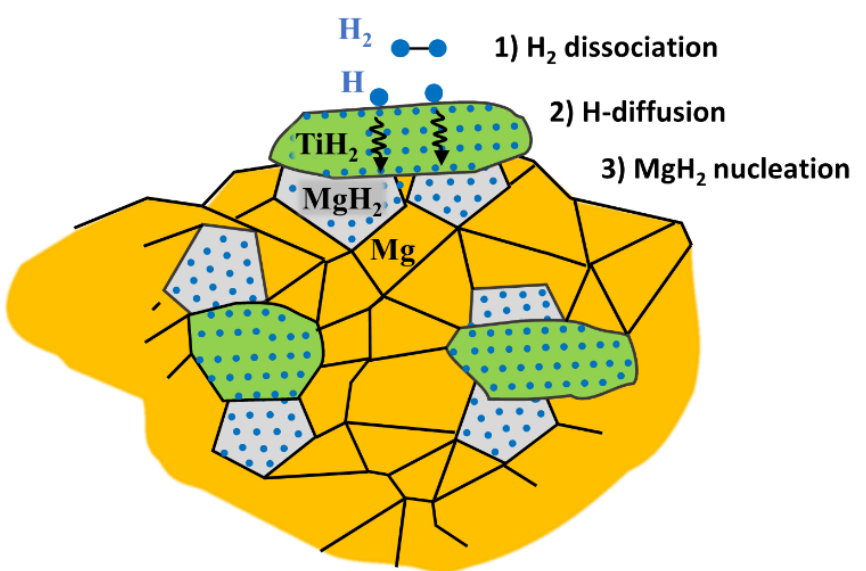

Figure 10. Schematic representation of a $\mathrm{Mg}-\mathrm{TiH}_{2}$ nanocomposite showing the role of $\mathrm{TiH}_{2}$ (in green) to enhance hydrogen sorption kinetics in $\mathrm{Mg}$ (orange). $\mathrm{TiH}_{2}$ helps to 1) dissociate $\mathrm{H}_{2}$ molecules (in blue), 2) to transfer $\mathrm{H}$ atoms to the $\mathrm{TiH}_{2} / \mathrm{Mg}$ interface and 3) to facilitate $\mathrm{MgH}_{2}$ (in grey) nucleation. 


\section{Conflicts of interest}

There are no conflicts to declare.

\section{Acknowledgements}

Dr. Pavel Rizo-Acosta thanks the Mexican government for his support through a SENER-CONACYT PhD grant. The authors are also grateful to Dr. Jean-Claude Crivello (ICMPE/CNRS) for his critical reading of the manuscript.

\section{References}

1 R. Weast, M. Astle and W. Beyer, in CRC handbook of chemistry and physics: A ready-reference book of chemical and physical data, Boca Raton, Fla: CRC Press, 1984.

2 K.-F. Aguey-Zinsou and J.-R. Ares-Fernández, Energy Environ. Sci., 2010, 3, 526.

3 J.-C. Crivello, B. Dam, R. V. Denys, M. Dornheim, D. M. Grant, J. Huot, T. R. Jensen, P. de Jongh, M. Latroche, C. Milanese, D. Milčius, G. S. Walker, C. J. Webb, C. Zlotea and V. A. Yartys, Appl. Phys. A, 2016, 122, 97.

4 A. San-Martin and F. D. Manchester, J. Phase Equilibria, 1987, 8, 431-437.

5 B. Vigeholm, K. Jensen, B. Larsen and A. Schrøder-Pedersen, J. Common Met., 1987, 131, 133-141.

6 T. Vegge, Phys. Rev. B, 2004, 70, 035412.

7 O. Friedrichs, J. C. Sánchez-López, C. López-Cartes, M. Dornheim, T. Klassen, R. Bormann and A. Fernández, Appl. Surf. Sci., 2006, 252, 2334-2345.

8 N. Gérard and S. Ono, in Topics in Applied Physics, ed. L. Schlapbach, Springer-Verlag, New York, 1992, vol. 67, pp. 178182.

9 J. F. Fernández and C. R. Sánchez, J. Alloys Compd., 2002, 340, 189-198.

10 X. Yao, Z. H. Zhu, H. M. Cheng and G. Q. Lu, J. Mater. Res., 2008, 23, 336-340.

11 F. Leardini, J. R. Ares, J. F. Fernández, J. Bodega and C. Sánchez, Int. J. Hydrog. Energy, 2011, 36, 8351-8357.

12 G. Liang, J. Huot, S. Boily, A. Van Neste and R. Schulz, J. Alloys Compd., 1999, 292, 247-252.

13 G. Barkhordarian, T. Klassen and R. Bormann, Scr. Mater., 2003, 49, 213-217.

14 C. J. Webb, J. Phys. Chem. Solids, 2015, 84, 96-106.

15 F. Tonus, V. Fuster, G. Urretavizcaya, F. J. Castro and J.-L. Bobet, Int. J. Hydrog. Energy, 2009, 34, 3404-3409.

16 D. Chen, Y. M. Wang, L. Chen, S. Liu, C. X. Ma and L. B. Wang, Acta Mater., 2004, 52, 521-528.

17 B. R. Pauw, W. P. Kalisvaart, S. X. Tao, M. T. M. Koper, A. P. J. Jansen and P. H. L. Notten, Acta Mater., 2008, 56, 2948-2954.

18 F. Cuevas, J.-F. Fernández, J. R. Ares, F. Leardini and M. Latroche, J. Solid State Chem., 2009, 182, 2890-2896.

19 J. F. Fernandez, J. R. Ares, F. Cuevas, J. Bodega, F. Leardini and C. Sánchez, Intermetallics, 2010, 18, 233-241.

20 K. Alsabawi, T. A. Webb, E. MacA. Gray and C. J. Webb, Int. J. Hydrog. Energy, 2017, 42, 5227-5234.

21 J. Huot, D. B. Ravnsbæk, J. Zhang, F. Cuevas, M. Latroche and T. R. Jensen, Prog. Mater. Sci., 2013, 58, 30-75.
22 R. W. P. Wagemans, J. H. van Lenthe, P. E. de Jongh, A. J. van Dillen and K. P. de Jong, J. Am. Chem. Soc., 2005, 127, 1667516680.

23 P. E. de Jongh and P. Adelhelm, ChemSusChem, 2010, 3, 13321348.

24 J.-L. Bobet, E. Akiba, Y. Nakamura and B. Darriet, Int. J. Hydrog. Energy, 2000, 25, 987-996.

25 G. Liang, J. Huot, S. Boily, A. Van Neste and R. Schulz, J. Alloys Compd., 1999, 2991, 295-299.

26 J. R. Ares, F. Cuevas and A. Percheron-Guégan, Acta Mater., 2005, 53, 2157-2167.

27 F. D. Manchester, Phase Diagrams of Binary Hydrogen Alloys, ASM International, Materials Park, $\mathrm{OH}, 2000$.

28 F. Cuevas, D. Korablov and M. Latroche, Phys. Chem. Chem. Phys., 2012, 14, 1200-1211.

29 X. Luo, D. M. Grant and G. S. Walker, J. Alloys Compd., 2015, 622, 842-850.

30 N. Patelli, M. Calizzi, A. Migliori, V. Morandi and L. Pasquini, J. Phys. Chem. C, 2017, 121, 11166-11177.

31 A. Zaluska, L. Zaluski and J. O. Ström-Olsen, J. Alloys Compd., 1999, 288, 217-225.

32 J. Huot, J. F. Pelletier, L. B. Lurio, M. Sutton and R. Schulz, J. Alloys Compd., 2003, 348, 319-324.

33 C. Ren, Z. Z. Fang, C. Zhou, J. Lu, Y. Ren and X. Zhang, J. Phys. Chem. C, 2014, 118, 21778-21784.

34 G. Liang, J. Huot, S. Boily and R. Schulz, J. Alloys Compd., 2000, 305, 239-245.

35 A. R. Yavari, J. F. R. de Castro, G. Vaughan and G. Heunen, J. Alloys Compd., 2003, 353, 246-251.

36 P. Rizo-Acosta, F. Cuevas and M. Latroche, Int. J. Hydrog. Energy, 2018, 43, 16774-16781.

37 M. Dornheim, S. Doppiu, G. Barkhordarian, U. Boesenberg, T. Klassen, O. Gutfleisch and R. Bormann, Scr. Mater., 2007, 56, 841-846.

38 J. Zhang, F. Cuevas, W. Zaïdi, J.-P. Bonnet, L. Aymard, J.-L. Bobet and M. Latroche, J. Phys. Chem. C, 2011, 115, 4971-4979.

39 J. Rodriguez-Carvajal, Phys. B, 1993, 192, 55-69.

40 H. M. Rietveld, J. Appl. Crystallogr., 1969, 2, 65-71.

41 B. O. Loopstra and H. M. Rietveld, Acta Crystallogr. Sect. B, 1969, 25, 787-791.

42 T. P. Blach and E. MacA. Gray, J. Alloys Compd., 2007, 446-447, 692-697.

43 B. Bogdanovic, K. Bohmhammel, B. Christ, A. Reiser, K. Schlichte, R. Vehlen and U. Wolf, J. Alloys Compd., 1999, 282, 8492.

44 M. V. Lototskyy, M. W. Davids, I. Tolj, Y. V. Klochko, B. S. Sekhar, S. Chidziva, F. Smith, D. Swanepoel and B. G. Pollet, Int. J. Hydrog. Energy, 2015, 40, 11491-11497.

45 M. Bortz, B. Bertheville, G. Böttger and K. Yvon, J. Alloys Compd., 20101120, 287, L4-L6.

46 S. Orimo, F. Kimmerle and G. Majer, Phys. Rev. B, 2001, 63, 94307-93316.

47 H. Müller and K. Weymann, J. -Common Met., 1986, 119, 115126.

48 J. J. Reilly and R. H. Wiswall, Inorg. Chem., 1970, 9, 1678-1682.

49 N. Berti, F. Cuevas, J. Zhang and M. Latroche, Int. J. Hydrog. Energy, 2017, 42, 22615-22621.

50 M. Ponthieu, F. Cuevas, J. F. Fernández, L. Laversenne, F. Porcher and M. Latroche, J. Phys. Chem. C, 2013, 117, 1885118862.

51 L. N. Yannopoulos, R. K. Edwards and P. G. Wahlbeck, J. Phys. Chem., 1965, 69, 2510-2515. 
52 A. Khawam and D. R. Flanagan, J. Phys. Chem. B, 2006, 110, $17315-17328$.

53 R. A. Varin, T. Czujko and Z. Wronski, Nanomaterials for solid state hydrogen storage, Springer, Cleveland, 2009.

54 S. Hao and D. S. Sholl, J. Phys. Chem. C, 2012, 116, 2045-2050.

55 V. A. Yartys, M. V. Lototskyy, E. Akiba, R. Albert, V. E. Antonov, J. R. Ares, M. Baricco, N. Bourgeois, C. E. Buckley, J. M. Bellosta von Colbe, J.-C. Crivello, F. Cuevas, R. V. Denys, M. Dornheim, M. Felderhoff, D. M. Grant, B. C. Hauback, T. D. Humphries, I. Jacob, T. R. Jensen, P. E. de Jongh, J.-M. Joubert, M. A. Kuzovnikov, M. Latroche, M. Paskevicius, L. Pasquini, L. Popilevsky, V. M. Skripnyuk, E. Rabkin, M. V. Sofianos, A. Stuart, G. Walker, H. Wang, C. J. Webb and M. Zhu, Int. J. Hydrog. Energy, 2019, 44, 7809-7859.

56 J. J. Reilly and R. H. Wiswall, Inorg. Chem., 1968, 7, 2254-2256.

57 J. N. Huiberts, R. Griessen, J. H. Rector, R. J. Wijngaarden, J. P. Dekker, D. G. de Groot and N. J. Koeman, Nature, 1996, 380, 231234.

58 J. Harris, Appl. Phys. A, 1988, 47, 63-71.

59 L. Schlapbach, in Hydrogen in Intermetallic Compunds II, Springer-Verlag, Berlin, 1992, pp. 15-95.

60 A. Züttel, M. Hirscher, B. Panella, K. Yvon, S. Orimo, B. Bogdanović, M. Felderhoff, F. Schüth, A. Borgschulte, S. Goetze, S. Suda and M. T. Kelly, in Hydrogen as a Future Energy Carrier, eds. A. Züttel, A. Borgschulte and L. Schlapbach, Wiley-VCH Verlag GmbH \& Co. KGaA, 2008, pp. 165-263.

61 Z. Wu, R. E. Cohen, D. J. Singh, R. Gupta and M. Gupta, Phys. Rev. B, 2004, 69, 085104.

62 J. N. Huiberts, J. H. Rector, R. J. Wijngaarden, S. Jetten, D. De Groot, B. Dam, N. J. Koeman, R. Griessen, B. Hjörvarsson and S. Olafsson, J. Alloys Compd., 1996, 239, 158-171.

63 J. H. Weaver, D. J. Peterman, D. T. Peterson and A. Franciosi, Phys. Rev. B, 1981, 23, 1692.

64 J. H. Weaver and D. T. Peterson, J. Common Met., 1980, 74, 207-216.

65 E. Nowicka and R. Duś, Langmuir, 1996, 12, 1520-1527.

66 G. Friedlmeier and M. Groll, J. Alloys Compd., 1997, 253-254, 550-555.

67 D. M. Borsa, R. Gremaud, A. Baldi, H. Schreuders, J. H. Rector, B. Kooi, P. Vermeulen, P. H. L. Notten, B. Dam and R. Griessen, Phys. Rev. B, 2007, 75, 205408-9.

68 U. Kaess, G. Majer, M. Stoll, D. T. Peterson and R. G. Barnes, J. Alloys Compd., 1997, 259, 74-82.

69 S. Hao and D. S. Sholl, Appl. Phys. Lett., 2008, 93, 251901.

70 J. Lu, Y. J. Choi, Z. Z. Fang, H. Y. Sohn, E. Rönnebro and E. H. Majzoub, J. Am. Chem. Soc., 2009, 131, 15843-15852.

71 J. Lu, Y. J. Choi, Z. Z. Fang, H. Y. Sohn and E. Rönnebro, J. Am. Chem. Soc., 2010, 132, 6616-6617.

72 T. Liu, C. Chen, F. Wang and X. Li, J. Power Sources, 2014, 267, 69-77.

73 C. Zhou, Z. Z. Fang and R. C. Bowman, J. Phys. Chem. C, 2015, 119, 22261-22271.

74 X. Ma, X. Xie, P. Liu, L. Xu and T. Liu, Prog. Nat. Sci. Mater. Int., 2017, 27, 99-104.

75 C. Zhou, Z. Z. Fang, R. C. Bowman, Y. Xia, J. Lu, X. Luo and Y. Ren, J. Phys. Chem. C, 2015, 119, 22272-22280.

76 S. Srinivasan, P. C. M. M. Magusin, W. P. Kalisvaart, P. H. L. Notten, F. Cuevas, M. Latroche and R. A. van Santen, Phys. Rev. B, 2010, 81, 054107.

77 K. Asano, H. Kim, K. Sakaki, K. Jimura, S. Hayashi, Y. Nakamura, K. Ikeda, T. Otomo, A. Machida and T. Watanuki, Inorg. Chem., 2018, 57, 11831-11838.
78 J. Cui, H. Wang, J. Liu, L. Ouyang, Q. Zhang, D. Sun, X. Yao and M. Zhu, J. Mater. Chem. A, 2013, 1, 5603-5611. 